\title{
Fine mapping a quantitative trait locus, qSER-7, that controls stigma exsertion rate in rice (Oryza sativa L.)
}

\author{
Yi Liu ${ }^{1,2+}$, Anning Zhang ${ }^{1,2+}$, Feiming Wang ${ }^{2}$, Deyan Kong ${ }^{2}$, Mingshou $\mathrm{Li}^{2}$, Junguo Bi ${ }^{2}$, Fenyun Zhang ${ }^{2}$,
} Jiahong Wang ${ }^{2}$, Xingxing Luo ${ }^{2}$, Zhongquan Pan ${ }^{2}$, Xinqiao Yü ${ }^{2}$ Guolan Liu ${ }^{2^{*}}$ (D) and Lijun Luo ${ }^{1,2^{*}}$

\begin{abstract}
Background: Stigma exsertion rate (SER) is a key determinant of outcrossing in hybrid rice seed production. A quantitative trait locus (QTL) for stigma exsertion rate in rice, QSER-7, has previously been detected on chromosome 7 by using a $\mathrm{F}_{2}$ population derived from two indica cytoplasmic male sterility (CMS) maintainers, Huhan 1B and II-32B.

Results: The chromosomal location of qSER-7 was precisely delimited by fine-scale mapping. Near-isogenic lines (NILs) were established, one of which isolated the locus in the GSER-711-32B line, which contains an introgressed segment of II$32 \mathrm{~B}$ in the Huhan $1 \mathrm{~B}$ genetic background, and exhibits a significantly higher stigma exsertion rate than that of the recurrent parent. Using 3192 individuals from the $\mathrm{BC}_{4} \mathrm{~F}_{2}$ segregation population, the QTL QSER-7 was narrowed down to a 28.4-kb region between the markers RM3859 and Indel4373 on chromosome 7. According to the rice genome annotation database, three genes were predicted within the target region. Real-time PCR analysis showed significantly higher expression levels of LOC_Os07g15370 and LOC_Os07g15390 in II-32B than in Huhan 1B. LOC_Os07g15370(OsNRAMP5) was a previously reported gene for $\mathrm{Mn}$ and $\mathrm{Cd}$ transporter. The stigma exertion rates of OsNRAMP5-overexpressing plants were significantly higher than that of wild type plants, in contrast, a T-DNA insertion mutant osnramp5 showed a lower stigma exertion rate.

Conclusions: In the present study, the QTL qSER-7 was isolated to a region between the markers RM3859 and Indel4373. Two candidate genes were selected based on the expression difference between the two parents, which can facilitate the further cloning of the gene underlying the quantitative trait associated with aSER-7 as well as the marker-assisted transfer of desirable genes for stigma exsertion rate improvement in rice.
\end{abstract}

Keywords: Rice (Oryza sativa L), Quantitative trait locus, Stigma exsertion rate, Fine mapping

\section{Background}

Rice (Oryza sativa L.) is a major cereal crop that feeds most of the world's population. By 2030, rice production must increase at least $40 \%$ in order to satisfy demands of the ever-growing human population (Khush 2005). Accordingly, it is inevitable that rice production will have a direct effect on global food security and social stability. The commercialization of hybrid rice initiated in China in the 1970s has greatly contributed to the increase in rice yield (Stuber 1994; Yuan 2004). The basis of utilizing heterosis

\footnotetext{
* Correspondence: guolanliu@126.com; lijun@sagc.org.cn

†Yi Liu and Anning Zhang contributed equally to this work.

${ }^{2}$ Shanghai agrobiological gene center, Shanghai 201106, People's Republic of China

'Huazhong agricultural university, Wuhan 430070, People's Republic of China
}

in rice is to use male sterile lines (cytoplasmic male sterility lines or thermo-sensitive genic male sterile lines) as the female parents. However, despite continuous improvements in cultivation techniques for $\mathrm{F}_{1}$ seed production over the last 10 years, the yield of hybrid rice seed production has stagnated at 2.5 tons per hectare (Xie 2009). The low outcrossing rate of the maternal parent is the main factor limiting further increases in the $F_{1}$ seed production yields in rice because it is a typically self-pollinated crop (Kato and Nimai 1987). The rice flowers receive pollen on their stigmas, and exserted stigmas extend past the floral organ known as a glume; rice stigmas remain receptive for approximately 4 days, and thus exserted stigmas have more opportunities to trap pollen from other rice genotypes, 
thereby improving cross-pollination rates(Long and Shu 2000; Tian et al. 2004). The stigma exsertion rate is a major factor that contributes to the efficient improvement of hybrid seed production.

Many studies have shown that stigma exsertion in rice is a complex quantitative trait governed by polygenetic inheritance. In the past two decades, with the development of genomics and molecular markers, a QTLs for stigma exsertion in rice have been mapped by using different segregating populations such as $F_{2}$ populations (Xiong et al. 1999; Yue et al. 2009; Deng et al. 2010; Feng et al. 2010; Li et al. 2010; Deng et al. 2011; Chen et al. 2011; Li et al. 2017); recombinant inbred lines (Uga et al. 2003; Yamamoto et al. 2003; Shen et al. 2006; Yu et al. 2006; Yin et al. 2014; Li et al. 2014; Rahman et al. 2016); doubled haploid lines (Hittalmani et al. 2002; Li et al. 2003); backcrossing populations ( $\mathrm{Li}$ et al. 2001; Miyata et al. 2007; Qiao et al. 2007; Qiao et al. 2008); and chromosome segment substitution lines (Liu et al. 2015; Rahman et al. 2017a; Rahman et al. 2017b). Genome-wide association studies (GWAS) have more recently been employed to identify loci associated with stigma exsertion (Yan et al. 2009; Huang et al. 2012; Dang et al. 2016; Zhou et al. 2017; Guo et al. 2017). The QTLs that affect stigma exsertion were distributed across all 12 rice chromosomes. Nevertheless, only a small handful of QTLs explained more than $10 \%$ of the phenotypic variation. And a small proportion of these QTLs have been fine mapped or cloned. The major QTL qES3 was repeatedly identified and co-located with the grain size gene GS3 (Yamamoto et al. 2003; Miyata et al. 2007). Takano-Kai et al. (2011) confirmed that GS3 controls both stigma length and exsertion. They also demonstrated that a nonsense mutation in the second exon of GS3 increased cell number in the stigma, resulting in elongation and exsertion of the stigma. Liu et al. (2015) fine mapped the QTL qSTL3, which is associated with stigma length, to a $19.8-\mathrm{kb}$ region in the middle of the short arm of chromosome 3 and validated $L O C_{-}$ OsO3g14850 as a candidate gene associated with qSTL3. They also developed a gene-specific marker for improving the stigma length of the maternal parent, thereby increasing the outcrossing rate of the maternal parent in japonica hybrid seed production. Rahman et al. (2017a) dissected a major QTL (qSE11) and narrowed its location to a $350.7-\mathrm{kb}$ region on rice chromosome 11 . Despite so many QTLs having been identified, the genetic mechanism underlying stigma exsertion rate is poorly understood and requires further investigation.

In our previous study, the main effect QTL qSER-7 was localized to the rice chromosome 7 region flanked by markers RM3859 and RM5436 using a $F_{2}$ population derived from two indica CMS maintainers, Huhan $1 \mathrm{~B}$ and II-32B. The positive effect of $q S E R-7$ was from the high stigma exsertion rate parent II-32B improved both single stigma exsertion and total stigma exsertion rates, explaining $8.12 \%$ and $8.15 \%$ phenotypic variation, respectively(Yue et al. 2009).

In the present study, we performed fine-linkage mapping of $q S E R-7$ by using a $\mathrm{BC}_{4} \mathrm{~F}_{2}$ segregation population derived from Huhan $1 \mathrm{~B}$ and II-32B. Ultimately, the location of $q S E R-7$ was narrowed down to a $28.4-\mathrm{kb}$ region on rice chromosome 7 flanked by the RM3859 and Indel4373 markers. We also analyzed key candidate genes in that region that may be the target gene related to stigma exsertion. These results will be useful for facilitating the development of male sterile lines with high stigma exsertion rates, which would be of great value in hybrid rice seed production.

\section{Results}

\section{Development of the near isogenic line for $9 S E R-7$}

Based on previous research, qSER-7 was mapped to between markers RM3859 and RM5436 (Yue et al. 2009). Substitution mapping was used to isolate $q S E R-7$ and one line from the $F_{2}$ population was selected for four rounds of backcrossing with Huhan $1 B$ (Fig. 1). The simple sequence repeat (SSR) markers RM3859 and RM5436 were used in marker-assisted selection for segregating the progenies carrying the II-32B qSER-7 allele during each backcross generation. After continuous backcrossing for four generations and selfing, the genetic background became relatively similar to that of the recurrent parent Huhan 1B except for the substituted target segments, for which the $\mathrm{BC}_{4} \mathrm{~F}_{2}$ plants were scanned with a set of 102 SSR markers that were uniformly distributed across a previous linkage map (Additional file 1: Table S1). The individual plant exhibiting the maximum recurrent parent genome recovery $(94.11 \%)$ was selected, i.e., NIL $\left(q S E R-7^{\mathrm{II}-32 \mathrm{~B}}\right)$, which carried a homozygous introgression from II-32B across the entire $q S E R-7$ region in the Huhan1B genetic background (Fig. 2).

\section{Phenotypic and genetic analysis}

The stigma exsertion rate of the recurrent parent Huhan $1 \mathrm{~B}$ was $27.93 \%$ (single stigma exsertion rate, SSE), $9.08 \%$ (dual stigma exsertion rate, DSE), and $37.01 \%$ (total stigma exsertion rate, TSE), whereas the NIL ( $\left.q S E R-7^{\mathrm{II}-32 \mathrm{~B}}\right)$ phenotypic traits were higher (43.84\%, $17.26 \%$, and $61.10 \%$, respectively). Thus, the NIL ( $\left.q S E R-7^{\mathrm{II}-32 \mathrm{~B}}\right)$ had increased exsertion rates of $15.91 \%, 8.25 \%$ and $24.09 \%$ (SSE, DSE, and TSE, respectively), compared to the recurrent parent Huhan 1B (Table 1, Fig. 3). This result indicates that qSER7 is responsible for the high stigma exsertion rate in NIL (qSER-7 $\left.{ }^{\mathrm{II}-32 \mathrm{~B}}\right)$.

Among the random selection of 120 individuals in the $\mathrm{BC}_{4} \mathrm{~F}_{2}$ population, the marker RM3859 was used to validate the effect of $q S E R-7$. The result of a Chi-squared 


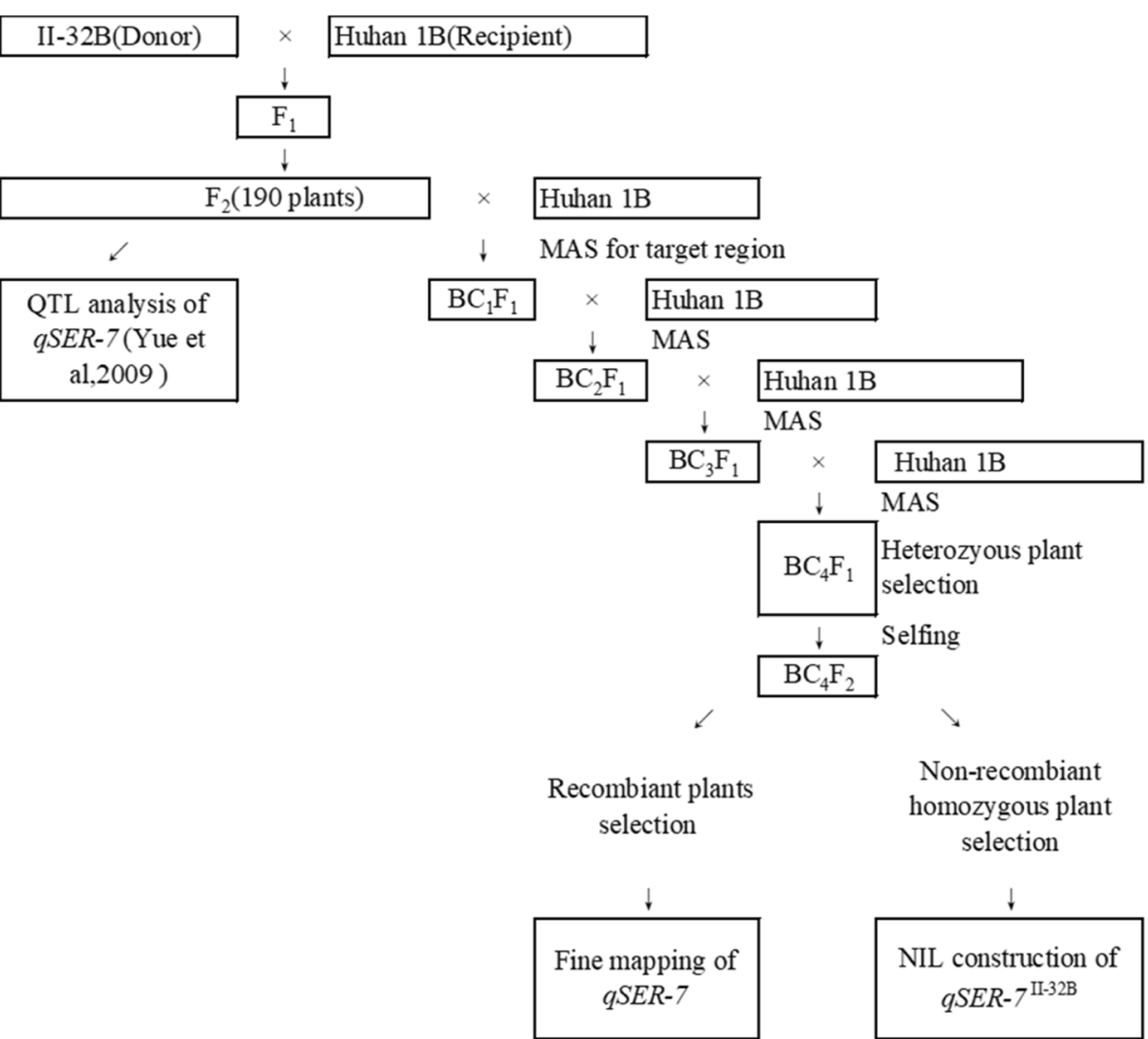

Fig. 1 The scheme of plant population development for QTL analysis, NIL construction and QTL fine mapping

test showed that the three genotypes were distributed according to 1:2:1 Mendelian ratio $\left(X^{2}=1.38<\chi_{0.05,2}^{2}=5.99\right)$ . The total stigma exsertion rates of II-32B homozygotes and heterozygotes were significantly higher than that of Huhan1B homozygotes, indicating that the effect of $q S E R$ 7 is likely controlled by one genetic locus (Table 2).

\section{Homozygous recombinant plant selection and fine mapping of $q S E R-7$}

The SSR marker RM3859 on one side of the qSER-7 target region and RM5436 on the other side were used to identify recombination break points in segregating progenies. To narrow down the location of $q S E R-7$, we developed six additional InDel markers (Additional file 2: Table S2). A total of $3192 \mathrm{BC}_{4} \mathrm{~F}_{2}$ progenies were cultivated in order to screen for recombinants, and 18 heterozygous individuals were selected and selfed to generate individuals with homozygous genotypes. Six different $\mathrm{BC}_{4} \mathrm{~F}_{3: 4}$ homozygous recombinant lines (R1-R6) in the QTL region were analyzed for fine mapping. The phenotypic performance of the stigma exsertion rates varied from $40.25 \%$ to $68.31 \%$ (Fig. 4b) in the homozygous recombinant lines. The total stigma exsertion rates of R1, R3, and R5 were similar to that of the 'Huhan $1 \mathrm{~B}$ ' recurrent parent; however, R2, R4, and R6 had significantly higher stigma exsertion rates similar to that of II-
32B donor parent. Based on the genetic and phenotypic analysis, the location of $q S E R-7$ was finally narrowed to a 28.4-kb region between the RM3859 and Indel4373 markers (Fig. 4b).

\section{Candidate gene analysis for $9 S E R-7$}

According to the rice genome annotation database (http:// rice.plantbiology.msu.edu/, MSU- version_7.0), three genes were predicted in the mapping region: $L O C_{-}$ Os07g15370, LOC_Os07g15390 and LOC_Os07g15400 (Fig. 4c). LOC_Os07g15370 (OsNRAMP5) was reported to be a $\mathrm{Mn}$ and $\mathrm{Cd}$ transporter involved in the root uptake of these metals from the medium (Ishikawa et al. 2012; Yang et al. 2014); LOC_OsO7g15390 and LOC_ Os07g15400 putatively encode a retrotransposed protein and expressed protein, respectively. We performed a quantitative reverse transcription-PCR (RT-PCR) analysis to determine the candidate genes, and the analysis revealed that the expression level of LOC_Os07g15370 and LOC_Os07g15390 were significantly higher in II-32B and NIL ( $\left.q S E R-7^{\mathrm{II}-32 \mathrm{~B}}\right)$ compared with Huhan 1B, however, no significant difference was observed in $L O C_{-}$ OsO7g15400 (Fig. 5). Therefore, LOC_Os07g15370 and LOC_Os07g15390 were likely to be the candidate genes for qSER-7. 


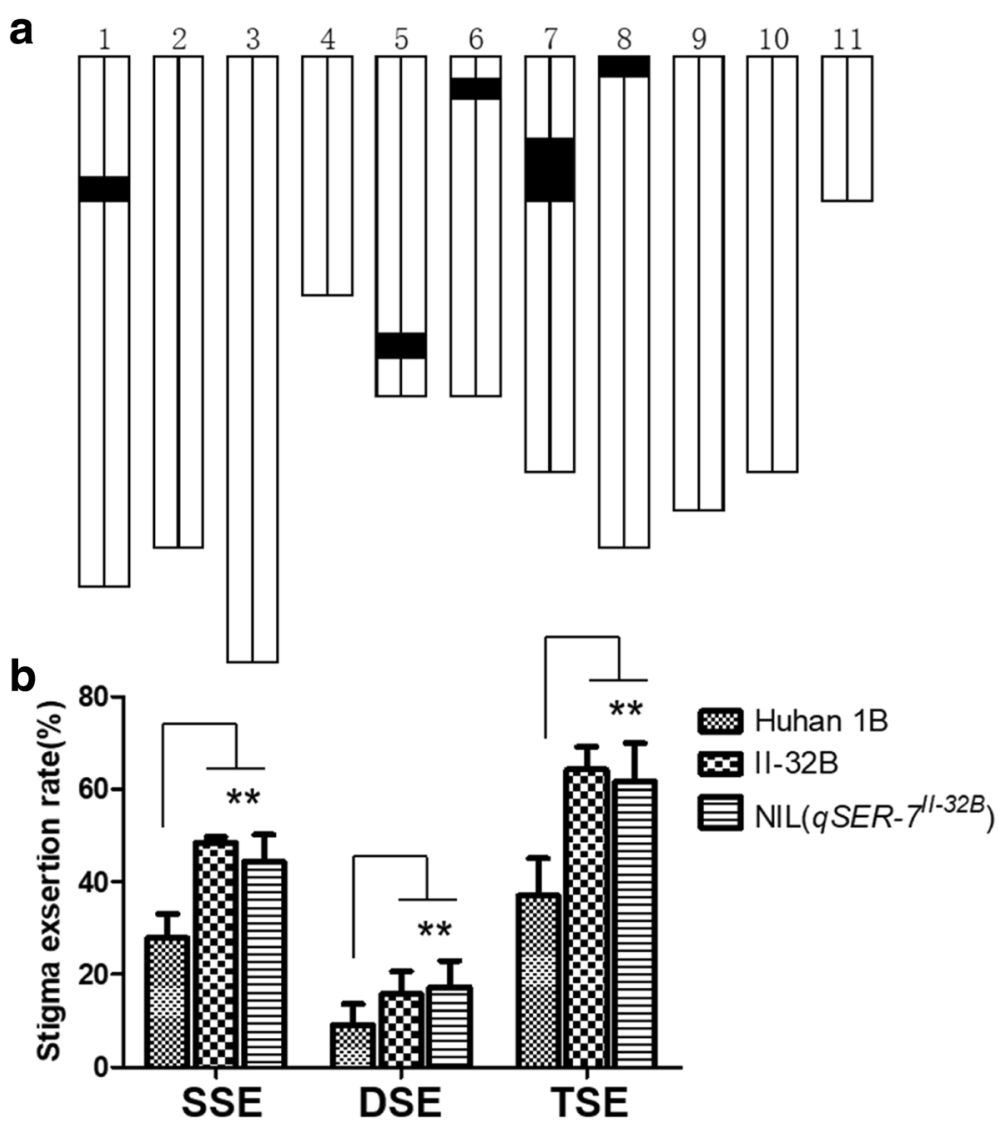

Fig. 2 The development of NIL. a Graphical genotype of NIL ( $\left(\right.$ SER- $7^{11-32 B}$ ). Black bar indicates the genome fragment from II-32B; the other parts were from Huhan 1B. b Stigma exertion rate for Huhan 1B, II-32B and NIL (qSER-71-32B). SSE: single stigma exsertion rate, DSE: dual stigma exsertion rate, TSE: total stigma exsertion rate. The data represent the mean \pm SD $(n=10),{ }^{*} P \leq 0.01$

Sequence comparison between II-32B and Huhan1B revealed no coding sequence polymorphisms differentiating these two genes. For LOC_Os07g15370, a single 1bp deletion was identified in the promoter region between the parental lines. For LOC_Os07g15390, 16 single-base substitutions were found in the promoter sequence (Additional file 3: Table S3), suggesting that the effect at $q S E R-7$ might result from a difference in expression levels between II-32B and Huhan1B alleles.

A T-DNA insertion mutant osnramp5, OsNRAMP5-overexpressing transgenic rice plants and wild type (Zhonghua 11) plants were obtained from Yang et al. (2014) for preliminary phenotypic evaluation. Compared to wild type plants, the stigma exertion rates of OsNRAMP5-overexpressing plants (OE5 and OE8 lines) were significantly higher; in contrast, the stigma exertion rates of the osnramp5 mutant was significantly lower than that of wild type plants (Fig. 6, Additional file 4: Figure S1).

\section{Discussion}

Stigma exertion rate is a female parental trait that is essential for improving hybrid seed production in rice. Exerted stigmas are fragile and thus can be easily damaged by environmental conditions such as wind, water stress, and physical disruption during the flowering period (Yu et al. 2006; Yan et al. 2009). A number of SER QTLs have previously been detected and are distributed across all 12 chromosomes in rice. However, the

Table 1 The stigma exsertion rates of Huhan 1B, II-32B and NIL (qSER-71-32B

\begin{tabular}{llll}
\hline Traits & Huhan 1B & II-32B & NIL (qSER-71-32B $)$ \\
\hline Single stigma exsertion rate (\%) & $27.93 \pm 5.00$ & $48.50 \pm 1.19$ & $43.84 \pm 7.49$ \\
Dual stigma exsertion rate (\%) & $9.08 \pm 4.38$ & $15.73 \pm 4.74$ & $17.26 \pm 5.39$ \\
Total stigma exsertion rate (\%) & $37.01 \pm 7.80$ & $64.23 \pm 4.77$ & $61.10 \pm 9.48$
\end{tabular}

NIL ( $\left.q S E R-7^{11-32 B}\right)$, is a near isogenic line carrying the homozygous $q S E R-7$ region from II-32B on Huhan $1 \mathrm{~B}$ genetic background. Trait values are shown as mean \pm standard deviation values 

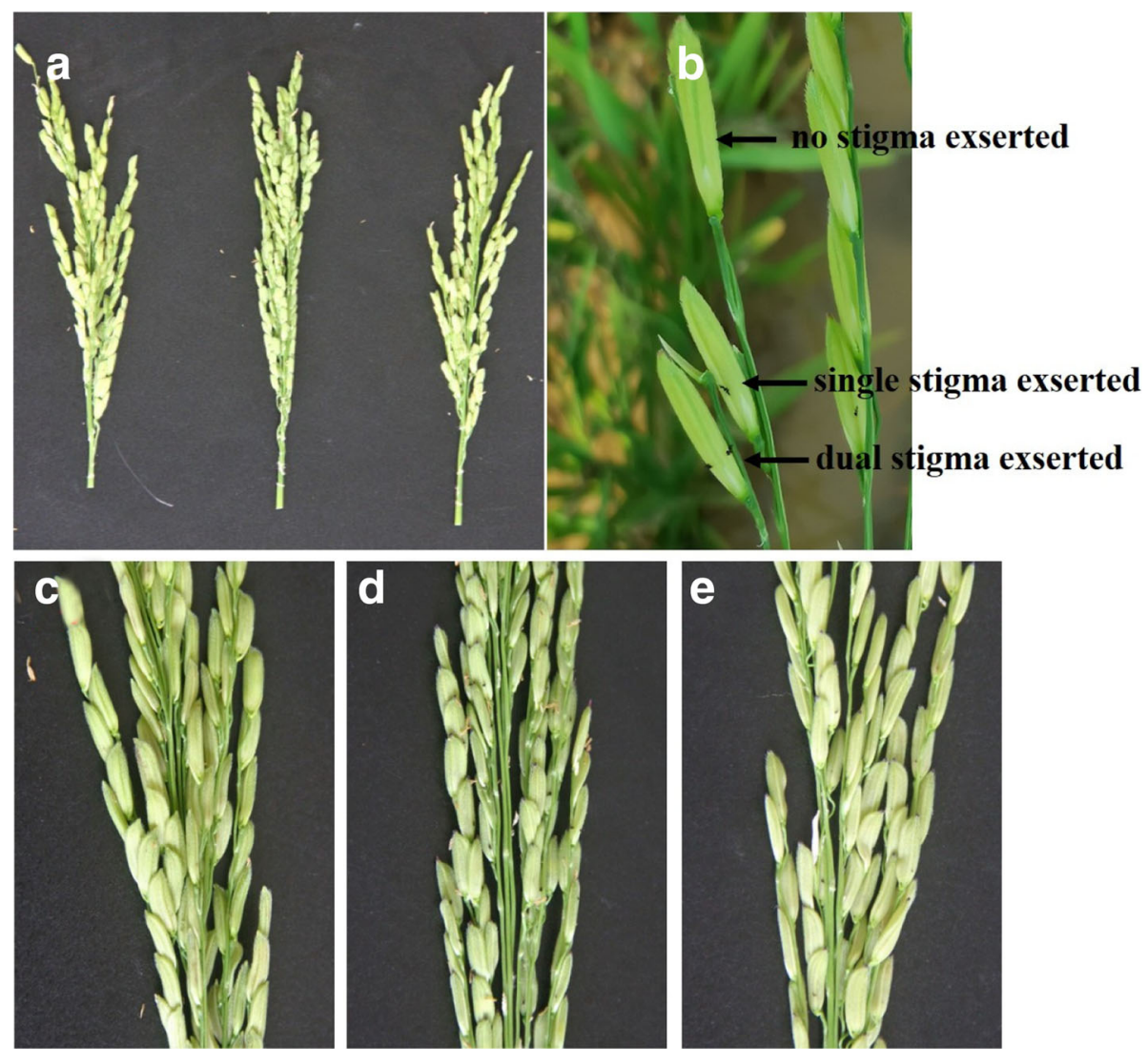

Fig. 3 The phenotype of the stigma exsertion of the parents Huhan 1B, II-32B, and NIL ( 9 SER-71-32B). aThe panicles of the parental lines shown from the left to the right are Huhan 1B, II-32B, and NIL ( $\left(\right.$ SEER-7 $7^{11-32 B}$ ). b Examples of single, dual, and no stigma exsertion in a spikelet, $\mathbf{c}$ Huhan 1B (stigmas are brown). d II-32B (stigmas are black). e NIL (qSER-7 $\left.{ }^{11-32 B}\right)$

results of these QTL locations are not exactly consistent across population types, mark densities and analytical methods used by different studies. Previous studies have demonstrated that stigma exertion rate is significantly positively correlated with stigma length (Kato and Nimai 1987; Miyata et al. 2007). Currently, GS3 (Takano-Kai et al. 2011) and qSTL3 (Liu et al. 2015) are the only two cloned genes, that have been shown to increase stigma exsertion by increasing stigma length. However, neither of these two genes were cloned based on studies in which stigma exertion rate was the target trait. Recently, a major QTL (qSE11) for stigma exertion rate was narrowed to a $350.7-\mathrm{kb}$ region between the SE6-10 and SE10 markers on the long arm of rice chromosome 11 (Rahman et al. 2017a). One of the main reasons for slow progress in the fine-mapping of stigma exertion rate
QTL is that stigma exertion is strongly influenced by environment. To improve the accuracy of the phenotype assay, ten main panicles of parental and homozygous recombinant lines were collected at 5-7 days after heading, when the lower spikelets of the panicle had flowered, and stored at $-20^{\circ} \mathrm{C}$. Observation and counting were performed by the same person. Thus, the data generated in the present study with this technique provides an accurate description of stigma exsertion rate in the genotypes studied.

Development of NILs is a productive strategy for QTL confirmation and evaluation of their genetic effect, and it provides useful materials for population development during QTL fine mapping (Ding et al. 2011). One of the parents used in this study, Huhan1B, is the maintainer line of Huhan 1A, which is the first indica CMS line of

Table 2 Marker segregation and total stigma exsertion rate of the three genotypic groups in the $\mathrm{BC}_{4} \mathrm{~F}_{2}$ population

\begin{tabular}{|c|c|c|c|c|c|c|c|}
\hline \multirow[t]{2}{*}{ Marker } & \multicolumn{3}{|c|}{ Numbers of plants in the three genotypic groups } & \multirow[t]{2}{*}{$x^{2}(1: 2: 1)$} & \multicolumn{3}{|c|}{ Phenotypic of the three genotypic groups } \\
\hline & Huhan1B homozygote & Heterozygote & II-32B homozygote & & Huhan1B homozygote & Heterozygote & II-32B homozygote \\
\hline RM3859 & 25 & 61 & 34 & 1.38 & $39.16 \pm 7.14^{a}$ & $57.36 \pm 9.02^{b}$ & $62.17 \pm 11.42^{\mathrm{bc}}$ \\
\hline
\end{tabular}

The superscript letters indicate statistically significant differences $(p \leq 0.01)$ between the mean values within each row (Student's t-test). Phenotypic values are shown as mean \pm standard deviation values 


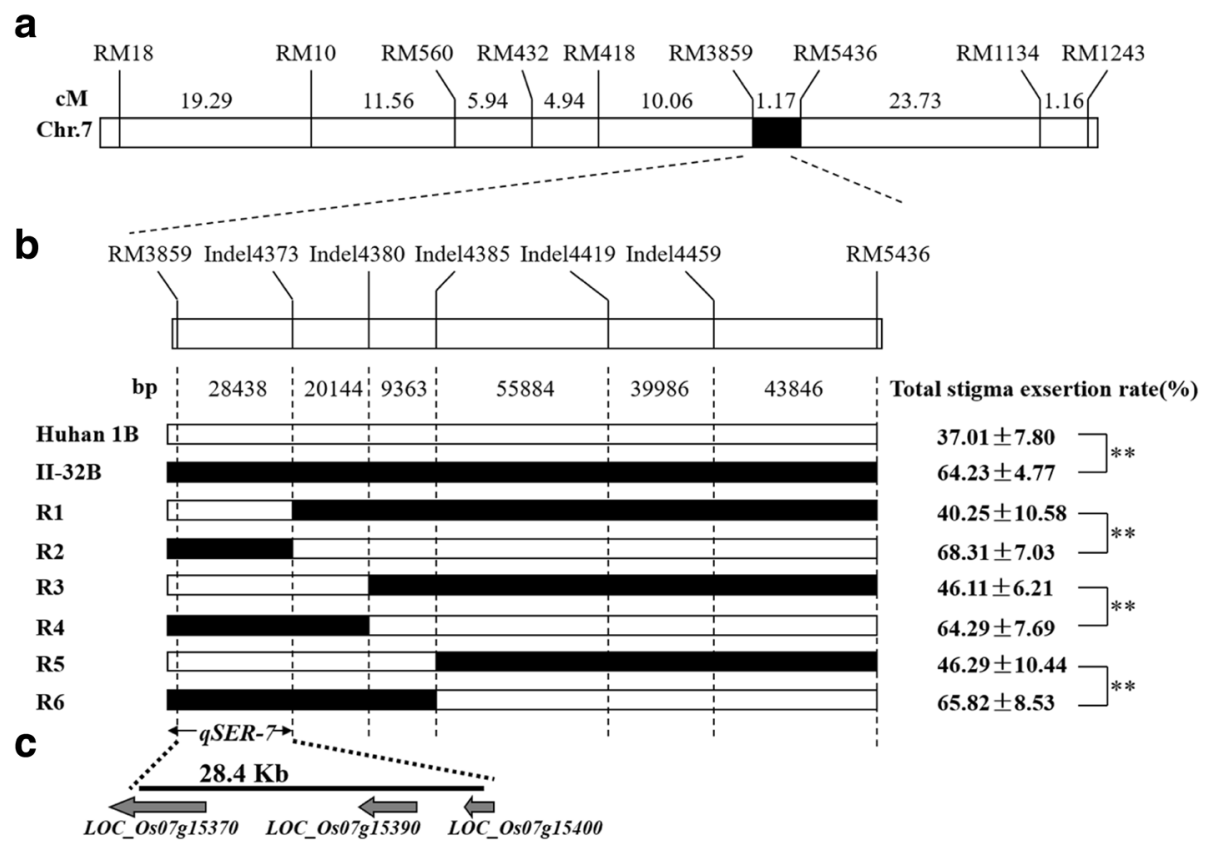

Fig. 4 Fine mapping of aSER-7. a The genetic linkage map of aSER-7 region on chromosome 7. The number between markers indicate genetic distance in centimorgans. b Fine mapping of the GSER-7 locus with six homozygous recombinants. Genotypes and phenotypes of homozygous recombinant lines $(\mathrm{R} 1-\mathrm{R} 6)$ were performed from $\mathrm{BC}_{4} \mathrm{~F}_{4}$ population. The qSER-7 was narrowed down to a 28.4-kb interval between the markers RM3859 and Indel4374. Black and white bars indicate homozygous for II-32B and Huhan 1B, respectively. The number between markers indicate physical distance. The data represent the mean \pm SD $(n=10)$, ${ }^{* *} P \leq 0.01$, t-test. c Candidate region of the qSER-7 locus and the annotated genes in the rice genome annotation database (http:// rice.plantbiology.msu.edu/, MSU- version_7.0)

water-saving and drought resistance rice (WDR) (Luo 2010). The NIL of $q S E R-7$ regions were constructed using Huhan1B as the recurrent parent. The NIL had increased rates of exsertion frequency of $15.91 \%, 8.25 \%$ and $24.09 \%$ (SSE, DSE, and TSE, respectively), compared to the recurrent parent Huhan1B. Thus, an improved version of Huhan1A carrying a homozygous qSER-7 region would shows a higher stigma exsertion rate and more hybrid seeds would be produced on a plant, and has therefore been widely used for WDR breeding.

A total of 10 QTLs for stigma exsertion rate were detected on chromosomes 3, 4, 7, and 9 in our previous study (Yue et al. 2009). The QTL flanked by RM3859 and RM5436 on chromosome 7, qSER-7, which had effects on single stigma exsertion and total stigma exsertion rate was dissected in this study. The qSER-7 region coincides with QTLs reported by Yin et al. (2014). In our report, qSER-7 was fine-mapped to a 28.4-kb region. The target region contains three predicted genes. $L O C_{-}$ Os07g15370 and LOC_Os07g15390 are likely to be the candidate genes according to the real time quantitative RT-PCR analysis. LOC_Os07g15370 (OsNRAMP5) was reported to be a $\mathrm{Mn}$ and $\mathrm{Cd}$ transporter involved in the root uptake of these metals from the medium (Ishikawa et al. 2012; Sasaki et al. 2012). Yang et al. (2014) found that OsNRAMP5 exhibited the strongest expression signal in young reproductive tissues, e.g., panicles and spikelets. Preliminary phenotypic evaluation showed that the stigma exertion rates of two OsNRAMP5-overexpressing plants (OE5 and OE8 lines) were significantly higher than that of wild type plants. Furthermore, more work, such as a transgenic complementary test, are needed to examine whether LOC_OsO7g15370 or LOC_ Os07g15390 is the most likely candidate underlying the effect of $q S E R-7$. Dissection of the genetic mechanisms for stigma exertion rate, which will facilitate rice molecular breeding for high stigma exsertion rate, will continue to improve the efficiency of hybrid seed production.

\section{Conclusion}

In this study using 3192 individuals from a $\mathrm{BC}_{4} \mathrm{~F}_{2}$ segregation population, a new QTL (qSER-7) for stigma exsertion rate, was fine mapped to within a 28.4-kb physical interval on chromosome 7. Two candidate genes were finally selected based on differences in transcriptional expression. The cloning and examination of the genetic study of the effect of $q S E R-7$ will facilitate increasing the stigma exsertion rate of male sterile lines and the further improvement of hybrid rice seed production. 

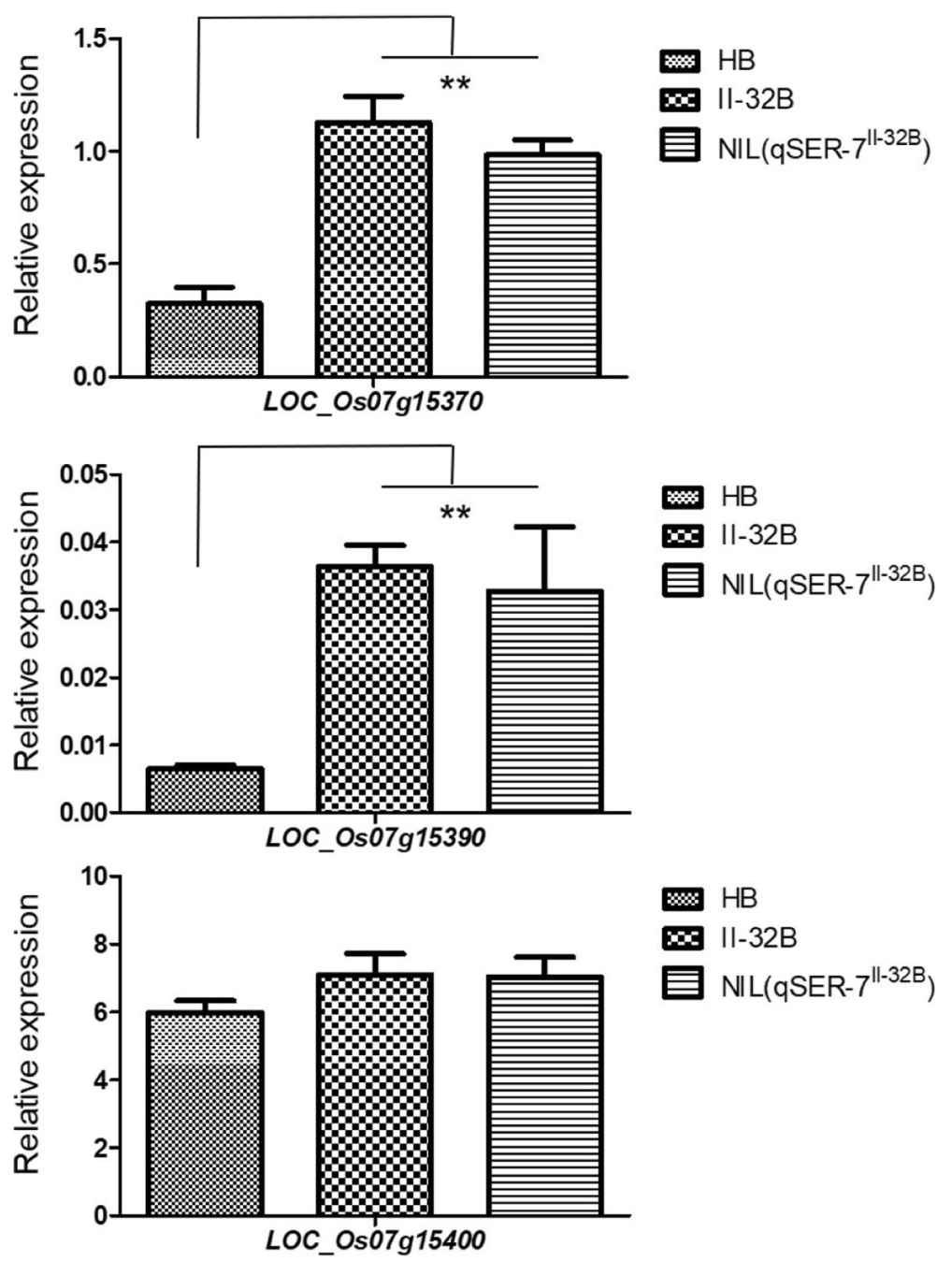

Fig. 5 The RT-PCR analysis of predicted genes in Huhan 1B, II-32B, and NIL ( $q$ SER- $7^{11-32 B}$ ) RNA was isolated from frozen young panicles (5 mm to $100 \mathrm{~mm}$ ). ${ }^{* *} \mathrm{P} \leq 0.01$, t-test. Values are the mean \pm SD with three biological replicates.

\section{Methods}

\section{Population and cultivation}

The detailed process of population development is illustrated in Fig. 1. In the previous study, the main effect QTL qSER-7 was detected for single stigma exsertion and total stigma exsertion rates using a $\mathrm{F}_{2}$ population derived from a cross between Huhan $1 \mathrm{~B}$ and II-32B (Yue et al. 2009). Huhan1B is the maintainer line for Huhan $1 \mathrm{~A}$, which is the first indica CMS line of water-saving and drought resistance rice (WDR) with a low stigma exsertion rate, whereas II-32B is the maintainer line of II-32A which has a good flowering habit and high stigma exsertion rate.

To obtain a relatively simple genetic background and to fine map the $q S E R-7$ locus, we constructed the NIL with respect to $q S E R-7$. To this end, an $\mathrm{F}_{2}$ line with the II-32B genotype in the qSER-7 region was selected to successively backcrossed with Huhan 1B for four generations. The SSR markers RM3859 and RM5436 were used for marker- assisted selection (MAS) of each generation among the segregating progenies. As a result, a $\mathrm{BC}_{4} \mathrm{~F}_{1}$ line with the Huhan $1 \mathrm{~B}$ genetic background, but exhibiting heterozygositys across the entire QSER-7 region was constructed. After selfing, we acquired a $\mathrm{BC}_{4} \mathrm{~F}_{2}$ line and used homozygous recombinants from the $\mathrm{BC}_{4} \mathrm{~F}_{4}$ generation for fine mapping of $q S E R-7$. Based on the genotypes of the II-32B alleles, one $\mathrm{BC}_{4} \mathrm{~F}_{2}$ plant with homozygous II-32B regions surrounding the qSER-7 allele with a single segment was chosen and named NIL $\left(q S E R-7^{\mathrm{II}-32 \mathrm{~B}}\right)$. A set of 102 simple sequence repeat (SSR) markers that were uniformly distributed on a previous linkage map (Yue et al. 2009) were used to screen the genetic background (Additional file 1: Table S1).

The $\mathrm{BC}_{4} \mathrm{~F}_{1}$ population was planted at Lingshui, Hainan Island, China, in winter 2015; the $\mathrm{BC}_{4} \mathrm{~F}_{2}$ population was planted at Shanghai, China, in summer 2016. The $\mathrm{BC}_{4} \mathrm{~F}_{3}$ and $\mathrm{BC}_{4} \mathrm{~F}_{4}$ populations were planted at Hainan in winter 2016 and Shanghai in summer 2017, respectively. 


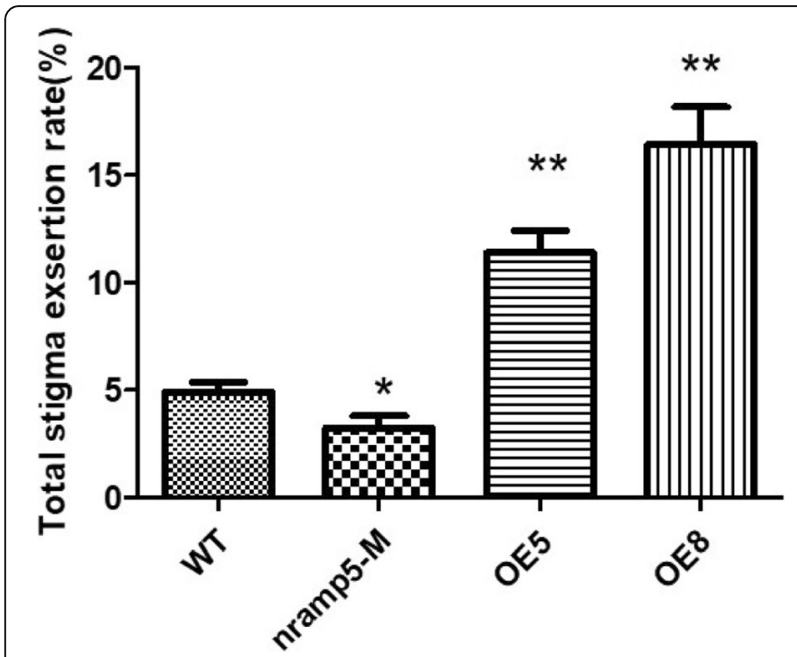

Fig. 6 Stigma exertion rate assay of osnramp5 mutant and OsNRAMP5 overexpressing transgenic rice. WT: wild type, OE5 and OE8: overexpressing transgenic lines, nramp5 M: osnramp5 mutant. The data represent the mean \pm SD $(n=10)$, ${ }^{*} P \leq 0.05$, ${ }^{*} P \leq 0.01$

Recombinant plants, NIL ( $\left.q S E R-7^{\mathrm{II}-32 \mathrm{~B}}\right)$ and their parents were established in five rows with seven plants per rows. Spacing was maintained at $30 \mathrm{~cm}$ between rows and 20 $\mathrm{cm}$ between plants. Standard crop management practices were followed.

Seeds of T-DNA insertion mutant, wild type (Zhonghua 11), and transgenic plants were obtained from Huazhong Agricultural University, Wuhan City, Hubei Province, China in 2016(Yang et al. 2014).

\section{Phenotypic evaluation}

The stigma exsertion rate was subdivided into three traits, single stigma exsertion rate (SSE), dual stigma exsertion rate (DSE) and total stigma exsertion rate (TSE). At 5-7 days after all spikelets had flowered, ten main panicles from parents and homozygous recombinant lines were collected for the examination of stigma exsertion rates. SSE, DSE, and TSE were calculated as the percentage of the numbers of spikelets with single stigma exsertion, dual stigma exsertion, and either single or dual stigma exsertion in the total number of spikelets, respectively.

\section{DNA extraction and development of molecular markers}

Total DNA was extracted from fresh leaves using the CTAB method (Murray and Thompson 1980). PCR was performed in $20-\mu \mathrm{L}$ reaction volumes containing $1.5 \mu \mathrm{L}$ of $20.0 \mathrm{ng} / \mu \mathrm{L}$ template DNA, $10 \mu \mathrm{L}$ of Taq PCR Mastermix (TIANGEN, Beijing, China), $2 \mu \mathrm{L}$ of $10 \mu \mathrm{mol} / \mu \mathrm{L}$ primer pairs, and $6.5 \mu \mathrm{L}$ of $\mathrm{ddH}_{2} \mathrm{O}$. The thermal cycling consisted of an initial denaturation at $95^{\circ} \mathrm{C}$ for $5 \mathrm{~min}$, followed by 35 cycles of denaturation at $95^{\circ} \mathrm{C}$ for $30 \mathrm{~s}$, annealing at $55^{\circ} \mathrm{C}$ for $30 \mathrm{~s}$ and extension at $72^{\circ} \mathrm{C}$ for 45 $\mathrm{s}$, with a final extension at $72{ }^{\circ} \mathrm{C}$ for $5 \mathrm{~min}$. The PCR products were separated on 6\% non-denatured polyacrylamide gels and detected by silver staining (Creste et al. 2001). Insertion/deletion (InDel) markers (Additional file 2: Table S2) were developed from the target region to determine recombination sites and the genotype of recombinant progenies based on the published rice DNA polymorphism database (Shen et al. 2004). The sequences of markers were designed using Primer Premier 5.0 (PREMIER Biosoft, Palo Alto, CA, USA).

\section{RNA extraction and real-time PCR analysis}

Total RNA was isolated from young panicles (Stage In7 to Stage In8, with a panicle lengths of 5 to $100 \mathrm{~mm}$ ) of Huhan $1 \mathrm{~B}$ and II-32B at the pre-heading stage using TRNzol-A+ Total RNA Reagent (TIANGEN, Beijing, China). cDNA was obtained via reverse transcription of total RNA using the PrimeScript RT reagent Kit (Takara Biotechnology, Dalian, China) and following the manufacturer's instructions. Real-time PCR was conducted using Hard-Shell 96-Well PCR Plates (BIO-RAD, Hercules, CA, USA), utilizing the CFX96TM Real-Time System (BIORAD). The utilized reaction system contained $10 \mu \mathrm{L}$ of $2 \times$ SYBR Premix Ex TaqTM (Takara Biotechnology, Dalian, China), 20 ng of cDNA, and $0.1 \mu \mathrm{M}$ of gene-specific primers (Additional file 2: Table S2) in a final volume of $20 \mu \mathrm{L}$. The thermal cycling conditions used were $95^{\circ} \mathrm{C}$ for $30 \mathrm{~s}$, followed by 40 cycles at $95^{\circ} \mathrm{C}$ for $5 \mathrm{~s}$, and $60^{\circ} \mathrm{C}$ for $31 \mathrm{~s}$, followed by a final extension stage. The housekeeping gene Actin2 was used as a reference gene for calculating the relative expression levels of each gene.

\section{Sequence and statistical analysis}

Gene-specific PCR primers were designed to amplify the promoters and coding regions of $q S E R-7$ candidate genes in the two parents (Additional file 2: Table S2). The reaction mixture $(50 \mu \mathrm{L})$ for the sequence analysis consisted of $2 \mu \mathrm{L}$ of template DNA/cDNA, $5 \mu \mathrm{L}$ of KODPCR Buffer, $5 \mu \mathrm{L}$ of $2 \mathrm{mM}$ dNTPs, $1 \mu \mathrm{L}$ each of $10 \mathrm{mM}$ forward and reverse primers, $3 \mu \mathrm{L}$ of $2.5 \mathrm{mM} \mathrm{MgSO}_{4}$, $0.5 \mathrm{U}$ of KOD enzyme, and $32 \mu \mathrm{L}$ of $\mathrm{ddH}_{2} \mathrm{O}$. The thermal cycling program included an initial denaturation at $95^{\circ} \mathrm{C}$ for $5 \mathrm{~min}$, followed by 35 cycles of denaturation at $95^{\circ} \mathrm{C}$ for $30 \mathrm{~s}$, annealing at $50{ }^{\circ} \mathrm{C}$ for $30 \mathrm{~s}$ and extension at $68{ }^{\circ} \mathrm{C}$ for $1 \mathrm{~min}$, with a final extension at $68^{\circ} \mathrm{C}$ for 5 min. The PCR products were then sub-cloned into the pEASY-Blunt cloning vector (TransGen Biotech, Beijing, China) according to the manufacturer's protocol. Positive clones were sequenced by the BioSune Company (Shanghai, China). The sequence results were analyzed using DNASTAR software (DNASTAR Inc., Madison, WI, USA). All statistical analyses were performed using Excel (Microsoft Corp., Redmond, WA, USA) and SPSS 17.0 (SPSS Corp., Chicago, IL, USA). 


\section{Additional files}

Additional file 1: Table S1. SSR markers selected to screen the genetic background. (DOCX $16 \mathrm{~kb}$ )

Additional file 2: Table S2. Primer sequences designed in this study. (DOCX $16 \mathrm{~kb}$ )

Additional file 3: Table S3. Comparison of promoter sequences of two candidate genes between two parents. (DOCX $15 \mathrm{~kb}$ )

Additional file 4: Figure S1. Relative expression levels of LOC_Os07g15370 in transgenic rice lines. (DOCX 55 kb)

\section{Abbreviations}

CMS: Cytoplasmic male sterility; DSE: Dual stigma exsertion rate" GWAS: Genome-wide association study; InDel: Insertion/deletion; MAS: Marker-assisted selection; NIL: Near isogenic line; QTL: Quantitative trait locus; SER: Stigma exsertion rate; SSE: Single stigma exsertion rate; SSR: Simple sequence repeat; TSE: Total stigma exsertion rate; WDR: Watersaving and drought resistance rice

\section{Acknowledgments}

We thank Dr. Xingming Lian at Huazhong Agricultural University for providing seeds of the mutant and transgenic plants.

\section{Authors' contributions}

$Y L, A N Z, G L L$ and $L L$ conceived and designed the experiments. FMW, DYK $J G B, F Y Z, J H W, X X L$ and ZQP performed the experiments. YL, XQY, GLL and $L \mathrm{~L}$ analyzed the data. $Y L$ wrote the paper. All authors read and approved the final manuscript.

\section{Funding}

This research was supported by the Shanghai Sailing Program (Grant No. 16YF1410000), Shanghai Agriculture Applied Technology Development Program (Grant No. 2017-02-08-00-08-F00071) and the Bill and Melinda Gates Foundation (Grant No. OPP1130530-4).

\section{Availability of data and materials}

All relevant data are provided as tables within the paper in the additional files.

\section{Ethics approval and consent to participate}

This study complied with the ethical standards of China, where this research work was carried out.

\section{Consent for publication}

All authors are consent for publication.

\section{Competing interests}

The authors declare that they have no competing interests.

Received: 30 January 2019 Accepted: 14 June 2019

Published online: 09 July 2019

\section{References}

Chen AG, Hua ZT, Wang L, Li ZB, Su YA (2011) Inheritance analysis and detection of QTLs for exserted stigma rate in rice. J Shenyang Agric Univ 42:142-146

Creste S, Neto AT, Figueira A (2001) Detection of single sequence repeat polymorphisms in denaturing polyacrylamide sequencing gels by silver staining. Plant Mol Bio Rep 19:299-306

Dang XJ, Liu EB, Liang YF, Liu QM, Breria CM, Hong DL (2016) QTL detection and elite alleles Mining for Stigma Traits in Oryza sativa by association mapping. Front Plant Sci 7:1188

Deng YD, Xiao CL, Deng HB, Zhang HQ, Deng XJ, Liu YL (2011) Detection of QTL related to stigma exsertion rate (SER) in rice (Oryza sativa L.) by bulked segregant analysis. Res Agric Modern 32:230-233

Deng YD, Ying JZ, Shi YY, Zhang HQ (2010) Mapping of QTLs for percentage of exserted stigma in rice. J Hunan Agric Univ 36:373-376

Ding XP, Li XK, Xiong LH (2011) Evaluation of near-isogenic lines for drought resistance QTL and fine mapping of a locus affecting flag leaf width, spikelet number, and root volume in rice. Theor Appl Genet 123:815-826
Feng LL, Jing YH, Huang C, Xu ZL, Chen WF (2010) QTL analysis of percentage of exserted stigma in rice (Oryza sativa L.). north. Rice 40:20-21

Guo L, Qiu FL, Gandhi H, Kadaru S, De Asis EJ, Zhuang JY, Xie FM (2017) Genome-wide association study of outcrossing in cytoplasmic male sterile lines of rice. Sci Rep 7:3223

Hittalmani S, Shashidhar HE, Bagali PG, Huang N, Sidhu JS, Singh VP, Khush GS (2002) Molecular mapping of quantitative trait loci for plant growth, yield and yield related traits across three diverse locations in a doubled haploid rice population. Euphytica 125:207-214

Huang X, Zhao Y, Wei XH, Li CY, Wang AH, Zhao Q, Li WJ, Guo YL, Deng LW, Zhu CR, Fan DL, Lu YQ, Weng QJ, Liu KY, Zhou TY, Jing YF, Si LZ, Dong GJ, Tao H, Lu TG, Feng Q, Qian Q, Li JY, Han B (2012) Genome-wide association study of flowering time and grain yield traits in a worldwide collection of rice germplasm. Nat Genet 44:32-39

Ishikawa S, Ishimaru Y, Igura M, Kuramata M, Abe T, Senoura T, Hase Y, Arao T, Nishizawa NK, Nakanishi H (2012) lon-beam irradiation, gene identification, and marker-assisted breeding in the development of low-cadmium rice. Proc Natl Acad Sci USA 109(47): 19166-19171.

Kato H, Nimai H (1987) Floral characteristics and environmental factors for increasing natural outcrossing rate for $\mathrm{F} 1$ hybrid seed production of rice Oryza sativa L. Jpn J Breed 37:318-330

Khush GS (2005) What it will take to feed 5.0 billion rice consumers in 2030. Plant Mol Biol 59:1-6

Li C, Sun CQ, Mu P, Chen L, Wang XK (2001) QTL analysis of anther length and ratio of stigma exsertion, two key traits of classification for cultivated rice (Oryza sativa L.) and common wild rice (O. rufipogon Griff.). Acta Genet Sin 28:746-751

Li HB, Gao FY, Zeng LH, Li QX, Lu XJ, Li ZH, Ren JS, Su XW, Ren GJ (2010) QTL analysis of rice stigma morphology using an introgression line from Oryza longistaminata L. Mol Plant Breed 8:1082-1089

Li PB, Feng FC, Zhang QL, Chao Y, Gao GJ, He YQ (2014) Genetic mapping and validation of quantitative trait loci for stigma exsertion rate in rice. Mol Breed $34: 2131-2138$

Li W, Sheng ZH, Zhu ZL, Wei XJ, Shi L, Wu YW, Tang SQ, Wang JL, Hu PS (2017) QTL mapping of japonica Rice stigma Exsertion rate. Chin J Rice Sci 31:23-30

Li WH, Dong GJ, Hu XM, Teng S, Guo LB, Zeng DL, Qian Q (2003) QTL analysis for percentage of exserted stigma in rice (Oryza sative L.). Acta Genet Sin 30:637-640

Liu QM, Qin JC, Li TW, Liu EB, Fan DJ, Edzesi WM, Liu JH, Jiang JH, Liu XL, Xiao LJ, Liu LL, Hong DL (2015) Fine mapping and candidate gene analysis of qSTL3, a stigma length-conditioning locus in rice (Oryza sativa L.). PLoS One 10: e0127938

Long LH, Shu K (2000) Increasing outcrossing rate of indica hybrid rice. J Hunan Agric Univ 26:205-208

Luo LJ (2010) Breeding for water-saving and drought-resistance rice (WDR) in China. J Exp Bot 61:3509-3517

Miyata M, Yamamoto T, Komori T, Nitta N (2007) Marker-assisted selection and evaluation of the QTL for stigma exsertion under japonica rice genetic background. Theor Appl Genet 114:539-548

Murray MG, Thompson WF (1980) Rapid isolation of high molecular weight plant DNA. Nucleic Acids Res 8:4321-4325

Qiao BJ, Huang LL, Jiang JH, Hong DL (2007) Mapping QTLs for four traits relating to outcrossing in rice (Oryza sativa L). J Nanjing Agric Univ 30:1-5

Qiao BJ, Zhu XB, Wang YY, Hong DL (2008) Mapping QTL for three panicle exsertion-related trais in rice (Oryza sativa L.) under different growing environments. Acta Agron Sin 34:389-396

Rahman MH, Yu P, Zhang YX, Sun LP, Wu WX, Shen XH, Zhan XD, Chen DB, Cao LY, Cheng SH (2016) Quantitative trait loci mapping of the stigma exertion rate and spikelet number per panicle in rice (Oryza sativa L.). Genet Mol Res 15:1-11

Rahman MH, Zhang YX, Sun LP, Zhang KQ, Rahman MS, Wu WX, Zhan XD, Cao LY, Cheng SH (2017a) Genetic mapping of quantitative trait loci for the stigma exsertion rate in rice (Oryza sativa L.). J Integr Agr 16:60345-60347

Rahman MH, Zhang YX, Zhang KQ, Rahman MS, Barman HN, Riaz A, Chen YY, Wu WX, Zhan XD, Cao LY, Cheng SH (2017b) Genetic dissection of the major quantitative trait locus (qSE11), and its validation as the major influence on the rate of stigma exsertion in rice (Oryza sativa L.). Front Plant Sci 8:1818

Sasaki A, Yamaji N, Yokosho K, Ma JF (2012) Nramp5 is a major transporter responsible for manganese and cadmium uptake in rice. The Plant Cell 24(5): 2155-2167.

Shen SQ, Zhuang JY, Bao JS, Shu QY, Xia YW (2006) Analysis of QTLs with main, epistasis and $\mathrm{G} \times \mathrm{E}$ interaction effects of stigma extruding trait in rice. J. Biomath 21:610-614 
Shen YJ, Jiang H, Jin JP, Zhang ZB, Xi B, He YY, Wang G, Wang C, Qian L, Li X, Yu QB, Liu HJ, Chen DH, Gao JH, Huang H, Shi TL, Yang ZN (2004) Development of genome-wide DNA poly-morphism database for map-based cloning of rice genes. Plant Physiol 135:1198-1205

Stuber CW (1994) Heterosis and hybrid rice breeding. Plant Breed 12:227-251

Tian DC, Huang SK, Duan YG, Wang YH (2004) The relationship between flowering and pollination time and outcrossing rate of male sterile lines in hybrid rice seed production. Hybrid Rice 19:50-54

Takano-Kai N, Doi K, Yoshimura A (2011) GS3 participates in stigma exsertion as well as seed length in rice. Breed Sci 61(3): 244-250.

Uga Y, Fukuta Y, Cai HW, Iwata H, Ohsawa R, Morishima H, Fujimura T (2003) Mapping QTLs inXuencing rice Xoral morphology using recombinant inbred lines derived from a cross between Oryza sativa L. and Oryza rufipogon Griff. Theor Appl Genet 107:218-226

Xie F (2009) Priorities of IRRI hybrid rice breeding. Accelerating hybrid Rice development, pp 49-62

Xiong LZ, Liu KD, Dai XK, Xu CG, Zhang Q (1999) Identification of genetic factors controlling domestication-related traits of rice using an F2 population of a cross between Oryza sativa and O. rufipogon. Theor Appl Genet 98:243-251

Yamamoto T, Takemori N, Sue N, Nitta N (2003) QTL analysis of stigma exsertion in rice. Rice Genet Newsl 20:33-34

Yan WG, Li Y, Agrama HA, Luo D, Gao F, Lu X, Ren G (2009) Association mapping of stigma and spikelet characteristics in rice (Oryza sativa L.). Mol Breed 24: 277-292

Yang M, Zhang YY, Zhang L, Hu JT, Zhang X, Lu K, Dong HX, Wang DJ, Zhao FJ, Huang CF, Lian XM (2014) OsNRAMP5 contributes to manganese translocation and distribution in rice shoots. J Exp Bot 65:4849-4861

Yin C, Li PB, Gao GJ, Zhang QL, Luo LJ, He YQ (2014) QTL analysis of percentage of exserted stigma in rice. Mol Plant Breed 12:43-49

Yu XQ, Mei HW, Luo L, Liu LG, Liu HY, Zou GH, Hu SP, Li MS, Wu JH (2006) Dissection of additive, epistatic effect and $\mathrm{Q} \times \mathrm{E}$ interaction of quantitative trait loci influencing stigma exsertion under water stress in rice. Acta Genet $\operatorname{Sin} 33: 542-550$

Yuan LP (2004) Hybrid rice technology for food security in the world. Crop Res 18:185-186

Yue GH, Mei HW, Pan LR, Lou J, Li MS, Luo LJ (2009) Mapping of QTLs affecting stigma exsertion rate of Huhan 1B as a CMS maintainer of upland hybrid rice. J Zhejiang Agric Univ 21:241-245

Zhou H, Li PB, Xie WB, Hussain S, Li YB, Xia D, Zhao H, Sun SY, Chen JX, Ye H, Hou J, Zhao D, Gao GJ, Zhang QL, Wang GW, Lian XM, Xiao JH, Yu SB, Li XH, He YQ (2017) Genome-wide association analyses reveal the genetic basis of stigma Exsertion in Rice. Mol Plant 10:634-644

\section{Publisher's Note}

Springer Nature remains neutral with regard to jurisdictional claims in published maps and institutional affiliations.

\section{Submit your manuscript to a SpringerOpen ${ }^{\circ}$ journal and benefit from:}

- Convenient online submission

- Rigorous peer review

- Open access: articles freely available online

- High visibility within the field

- Retaining the copyright to your article

Submit your next manuscript at $\boldsymbol{\nabla}$ springeropen.com 